Daniel $L$. Thornton is an assistant vice president at the Federal Reserve Bank of St. Louis. David Kelly provided research assistance.

\title{
Tests of Covered Interest Rate Parity
}

R terest in and investigations of whether the cov. ered interest parity (CIP) holds. At the microeconomic level, CIP is important because is it a direct consequence of covered interest arbitrage. Its failure to hold would suggest 1) that markets are inefficient in the sense that traders do not take advantage of known profit opportunities, 2) that legal restrictions and regulations, such as capital controls, exist or 3) that costs have been unaccounted for, such as individual borrowing constraints or differences in political risks across countries. ${ }^{1}$

At the aggregate level, CIP is important because it implies that interest rates and spot and forward exchange rates are related in a par. ticular way. Indeed, this relationship is frequently imposed in open-economy macroeco. nomic models. Finding that the relationship among these variables implied by CIP does not hold would leave their relationship uncertain. ${ }^{2}$

Generally, there have been two types of empirical investigations of CIP. The first are de. signed to determine whether markets are efficient in the sense that all known profit opportunities are arbitraged. "These tests investigate whether the actual forward premium deviates from that implied by CIP by more than the transaction costs using the most efficient arbitrage. The issues are whether the forward premia ever exceed estimates of the transaction costs and, if they do, whether they persist. The
In a sense, there are no tests of covered interest arbitrage. It is axiomatic! if tests revealed that CIP was violated so that known iskless profft opportunities were being ignored for long periods of time, such results would undoubtedly be explained in various ways, such as alleg. ing that relevant costs were ignored.

af CIP does not hold, it does not necessarily mean that there is no other exact linear relationship among these variables or their subsets. It only means that the nature of the relationship would be uncertain.

The policy implications of CIP may be especially important for small open economies where the U.S. interest rate can effectively be taken as exogenous. If ClP holds, attempts by such countries" policymakers to move their domestic in- terest rates will immediately get translated into their ex. change fates and vice versa. This is particularly true if the forward rate is an efficient predictor of the future spot rate. Even if this is not the case [for example, see Chrystal and Thornton (1988)], both forward and spot rates would likely be affected since they tend to move together. Furthermore, if CIP holds, such economies may be influenced more by external events, such as changes in U.S. monetary policy, than if CIP does not hold. See Dufey and Giddy (1978) and Kubarych (1983) for a discussion of some of the policy implications.

3For example, see Deardorff (1979), Callier (1981), Bahmani-Oskooee and Das (1985) and Clinton (1988). 
evidence is that frequent violations of CIP occur, but do not persist. ${ }^{4}$

The second tests are designed to examine whether CIP holds on average. 5 Specifically, they test whether domestic and foreign interest rates and spot and forward exchange rates respond in a way consistent with $\mathrm{CIP}$ to economic news that affects each market individually.

This article provides a generic representation of the latter tests and shows that, under appropriate conditions, similar tests can be performed that do not require testing the markets' response to particular sets of information. In so doing, this article extends empirical investigations to a larger set of countries and over a longer time period. ${ }^{6}$

\section{DORS CIP WOPD ON AVERAGE?}

CIP is a direct consequence of covered interest arbitrage. ${ }^{7}$ In the absence of transaction costs, the CIP condition requires that

(1) $\ln \left(1+i_{s}\right)-\ln \left(1+i_{\varepsilon}^{*}\right)-\ln F_{t}+\ln S_{1}=0$

where $i^{*}$ and $i$ are the foreign and U.S. interest rates, respectively, and $F_{t}$ and $S$, are the for. ward and spot foreign exchange rates (dollars per unit of foreign currency), respectively. ${ }^{8}$ The maturity of the U.S. and foreign assets and the forward contract are identical. Moreover, foreign and U.S. securities are assumed to be identical except for the currency in which future payments are denominated.

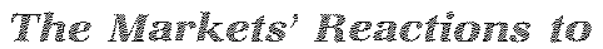

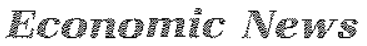

Equation 1 asserts that a particular linear combination of these variables is zero in the

4Much of this literature shows that the difference between the actual forward premium and that implied by CIP often fals outside of the neutral band given by transaction costs, e.g., see Bahmani-Oskooee and Das (1985) and Clinton (1988). For example, Clinton finds "that while the longest sequence of profitable trading opportunities is five observations [days], the most common rut does not extend beyond a single observation. Thus, in general, profit opportunities appear to be both small and short-lived, even though they are not rare." See Clinton (1988), p. 367. He suggests, however, that it is unlikely that the quality of the data will ever be sufficient to provide a rigorous test of market efficiency, i.e, that there are no unexplotted profit opportunities.

5To date, this work has relied exclusively on investigating markets' responses to money announcements. See Roley (1987), Husted and Kitchen (1985) and Tandon and Urich (1987).

6Roley (1987) considers Japan and only the Gensaki rate, while Husted and Kitchen (1985) use data for Canada and absence of transaction costs. Other linear combinations of the variables need not equal zero. Tests of CIP that rely on the markets' reactions to economic news or events make use of the fact that the particular linear combination of asset prices implied by CIP is zero. To see this, assume that U.S. and foreign interest rates and the spot and forward exchange rates can be represented by the following equations:

(2) $\sin \left(1+i_{\mathrm{r}}\right)=\mathrm{a}_{1}+\mathrm{b}_{\varepsilon} n_{\mathrm{t}}$

(3) $\Delta \ln \left(1+\mathrm{i}_{\mathrm{t}}^{*}\right)=\mathrm{a}_{2}+\mathrm{b}_{2} \mathrm{n}_{\mathrm{t}}$

(4) $\Delta \operatorname{lnF} F_{2}=a_{3}+b_{3} n_{1}$, and

(5) $\operatorname{sins} S_{1}=a_{4}+b_{4} n_{1}$,

where $n_{t}$ denotes the new information that becomes available in the interval over which the $t^{\text {th }}$ observation is made. Each asset may respond differently to the same news.

Investigations of CIP rely on testing the markets' responses to specific information by identifying a particular component of $n_{t}$ and by making an assumption about the stochastic properties of the rest. One approach is to estimate the equations

(6) $\sin \left(1+i_{1}\right)=a_{1}+d_{1} I_{1}+e_{1:}$

(7) $\sin \left(1+\mathrm{i}_{\mathrm{r}}^{*}\right)=\mathrm{a}_{2}+\mathrm{d}_{2} \mathrm{I}_{\mathrm{t}}+\mathrm{e}_{2 t}$

(8) $\Delta \operatorname{lnF}:=\mathrm{a}_{3}+\mathrm{d}_{3} \mathrm{I}_{4}+e_{3}$, and

(9) $\Delta \operatorname{lnS} S_{t}=a_{4}+d_{4} I_{t}+e_{4}$,

where $I_{L}$ denotes specific information that becomes available during the period in which the $t^{\text {th }}$ observation is made, and $e_{i t}=\left(b, e_{t}\right)$ denotes an individual market's response to all other information made available during the in-

Germany. Roley's data covers the period from October 6 , 1977 , through May 30, 1985, while Husted and Kitchen's data covers the period from February 8,1980 , through August 27, 1982.

7 Deardorff (1979) shows that covered interest arbitrage requires that the forward rate deviate from that implied by CIP by no more than $i t+t^{*}+t_{5}+t_{f} \frac{1}{\text {, where }} t, t^{*}$, $t$, and $t_{r}$ are the transaction costs (proportional to the size of the transaction) in the United States and foreign securities markets and the spot and forward foreign exchange markets, respectively. He also shows that the "neutral band" is narrower than this if "one-way" arbitrage is considered. This band has been further narrowed by Callier (1981), Bahmani-Oskooee and Das (1985) and Clinton (1988).

${ }^{\mathrm{a}} \mathrm{M} \mathrm{nF}$, and $\triangle \mathrm{MS}$, are weighted by an annualizing factor equal to 12 divided by the number of months in the forward contract. 
terval, $e_{\mathrm{t}}{ }^{9}$ Estimating this equation system involves the additional assumption that $\mathrm{E}_{(}\left(\mathrm{e}_{2}\right)=0$. Equations $6 \times 9$ are estimated and the restrictions $\mathrm{d}_{1}-\mathrm{d}_{2}-\mathrm{d}_{3}+\mathrm{d}_{4}=\mathrm{a}_{1}-\mathrm{a}_{2}-\mathrm{a}_{3}+\mathrm{a}_{4}=0$ are tested. If CIP holds, the intercept and slope coefficients of equations 6"9 will satisfy the particular homogenous linear restriction implied by CIP.

An asymptotically equivalent test can be performed by estimating the equation

$$
\text { (10) } \begin{aligned}
& \Delta \ln \left(1+\mathrm{i}_{\mathrm{t}}\right)-\Delta \ln \left(1+\mathrm{i}_{\mathrm{t}}^{*}\right)-\Delta \ln \mathrm{F}_{\mathrm{t}}+\Delta \ln \mathrm{S}_{\mathrm{t}}=\mathrm{a}+ \\
& \mathrm{dl} \mathrm{l}_{\mathrm{t}}+\mathrm{f}_{\mathrm{t}}
\end{aligned}
$$

and testing the hypothesis that $\mathrm{a}=\mathrm{d}=0$. In this form, the error term, $f_{t}=e_{1 t}-e_{2 t}-e_{3 t}+$ $e_{4}$, vanishes under the null hypothesis that the markets respond to the new information in a way consistent with CIP, that is, $b_{1}-b_{2}$ $-b_{3}+b_{4}=0$. A more satisfactory interpretation of $f_{L}$, therefore, comes from recalling that equation 1 holds identically only in the absence of transaction costs, so that $f_{1}$ represents the change in the log of these costs ${ }^{10}$

Another interpretation of $f_{t}$ stems from the fact that the observations used to examine CIP generally are not taken at the same time. To illustrate the effect of this, assume that observations on U.S. and foreign interest rates are taken at 3 a.m. EST, while the observations on the spot and forward exchange rates are taken at $11 \mathrm{a} . \mathrm{m}$. EST. The change in interest rates is measured from $3 \mathrm{a} . \mathrm{m}$. before the release of the specific information to 3 a.m. after the informa" tion is released. The change in the exchange rates is defined similarly. Under these assumptions, changes in the interest and exchange rates reflect information that is common to both, as well as the information unique to each. For example, changes in the interest rates will reflect the markets' reaction to information between $3 \mathrm{a} . \mathrm{m}$ and 11 a.m., but this information will not necessarily be reflected in the change in the exchange rates. Likewise, changes in the exchange rates reflect the markets' reaction to information from 3 a.m. to 11 a.m. the next day, but this information will not be reflected in the changes in the interest rates. Consequently, the error term of equation 10 comes potentially from differences in the information in the asset prices due to non-synchronous data, as well as from changes in the log of transaction costs. ${ }^{11}$ it could not come from the common information because, as we have already noted, this component of the error term vanishes under the null hypothesis. ${ }^{12}$

\section{Tests of the linear Pestrictions Implied by CIP}

A comparison of equations 6.9 and equation 10 reveals another interesting aspect of these tests. The hypothesis that $a=0$ is a test that the linear combination implied by CIP, but not accounted for by $I_{1}$, is zero. If CIP holds, this will be true at all limes, not simply when the 97his specification assumes that there is no idiosyncratic information that affects one market but not the others. It is difficult to see how such idiosyncratic information could exist in the reduced-form equations $6-9$, or how such an assumption could hold under the null hypothesis. For a model that looks at the implications of non-synchronous trading using the assumption of idiosyncratic information, see Lo and Mackinlay (1989).

folf transaction costs vary symmetricaly around a non-zero mean, the change in the log of transactions costs will not vary symmetrically around zero. This stems direcily from the concavity of the log function. This means that if the distribution of transactions cost is symmetric, the distribu tion of the log of the change in the transaction costs will be asymmetric,

"Since the markets may eventually respond to all information, the non-synchronous data implies that changes in asset prices taken at different periods of time will be serially correlated. In terms of equations $6 m 9$, this means that the error terms will be cross-sectionally autocorrelated. In terms of equation 10 , this implies that $f$ will be serially correlated. Indeed, when equation 10 was estimated using all of the daily data, this was the case. The results reported in this paper are for estimates of equation 10 only on days when the specific information was avaifable. Not surprisingly, in nearly all cases, these error terms were serially independent.
12For simplicity, let $\Delta i_{2}=\Delta \ln \left(1+i_{t}^{*}\right)-\Delta \ln \left(1+i_{i}^{*}\right)$ and $\Delta R=$ $\Delta \mathrm{inF}$ : $-\Delta \mathrm{n} \mathrm{S}$, so that CIP implies that $\Delta \mathrm{i}_{1}-\Delta \mathrm{F},=0$, under the simplifying assumption of zero transaction costs. Now let $\Delta i=a_{0}+\alpha, S I+\delta_{1}+\delta_{0} \eta$ and $\Delta \mathrm{R}=\beta_{1}+\beta_{1}$.

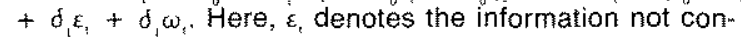
tained in that is reflected in both interest rates and ex change rates. $n$, denotes the information reflected in $\mathrm{Al}_{\text {, }}$ that is not reflected in $\Delta \mathrm{R}$, and $\omega$, denotes the information reflected in $\Delta F$, that cannot be reflected in $\Delta i_{\text {. }}$. Since there is little justification to do otherwise, it is assumed that $\Delta i$. responds the same to $\varepsilon_{t}$ and $\eta_{*}$; likewise, the response of $\Delta \mathrm{R}_{1}$ is the same for $\varepsilon_{1}$ and $\omega_{1}$. Note that if the response of these markets to information is consistent with CIP, i.e., $\left(\alpha_{0}-\beta_{0}\right)=\left(\alpha_{3}-\beta_{1}\right)=\left(\delta_{0}-\delta_{i}\right)=0, \Delta i_{3}-\Delta R$, differs from zero by $\delta_{0} \eta_{t}-\delta_{1} \omega_{t}$, the response to the nonsynchmonous information. [Estimation requires a normatiza tion; however, this does not affect the conclusion].

Aoley (1987), p. 65, asserts that, "when testing whether the responses of these variables to a specific piece of new information are inconsistert with covered interest parity, the exact alignment of the data is not necessary." "The above illustration demonstrates that this is not necessarily the case. The error term of equation 10 and, hence, the precision with which the parameters can be estimated is clearly dependent on the degree to which the data are synchronous. 
markets react to specific information. Tests of CIP using the markets' response to specific information generally are performed using data only for days when the information is released; however, evidence on CIP can be obtained directly from the changes in these four asset prices even if information that the markets respond to is not identified or is not available.

Rejecting the hypothesis that this linear combination of changes in asset prices is zero is strong evidence against CIP. A failure to reject the null hypothesis is not strong evidence in favor of it, however, because the same could be true for other linear combinations of these asset prices. If asset prices follow a random walk without drift, the same could be true for any linear combination of the change in these asset prices, not simply for the linear combination implied by CIP. Consequently, stronger evidence consistent with CIP would be obtained if the null hypothesis is not rejected for the linear combination implied by CIP, but is rejected for other linear combinations.

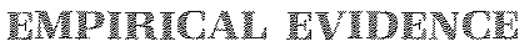

Tests of CIP using the markets' response to specific information have relied exclusively on their response to money announcements. In this section, the broader test outlined above is applied to daily data for the period from October 5, 1979, to September 14, 1988. Tests of CIP using the markets' response to information in the form of money announcements also are under" taken. The reported tests using money an* nouncements are only for days on which there was an announcement.

The data used in this study are one-, three-, six" and twelve-month Eurocurrency rates for the United States (U.S.), United Kingdom (U.K.), Canada (CA), Germany (GR), Switzerland (SW), France (FR) and Japan (JA), the corresponding forward exchange rates and the spot exchange

13The interest rates are from the BIS data tape at the Board of Governors of the Federal Reserve System. These are bid rates taken from several markets. The Money Market Service survey data through 1986 were provided by Graig Hakkio.

${ }_{14}^{4}$ For example, this is true of Tandon and Urich (1987), Husted and Kitchen ( $\$ 985)$ and Belongia and Sheehan (1987). Deaves, Melino and Pesando (1987), however. show that the significance of expected money on U.S. interest rates is due to a few outliers, while Belongia, Hafer and Sheehan (1986) have shown that the response of U.S. interest rates to anticipated money is very sensitive to the sample period. In any event, the presence or absence of rates. Anticipated changes in M1 are the median forecasts from the Money Market Services sur. vey, and the forecast error is the difference between the forecasted change and the change in first-announced M1. The interest rates are reported as of $3 \mathrm{a} . \mathrm{m}$. EST and the exchange rates are reported as of 11 a.m. EST. The interest rates are bid rates from the Bank of International Settlements. ${ }^{13}$ The exchange rates are the average of bid and ask rates from the London foreign exchange market.

The test of CIP using money announcements involves estimating the equation

$$
\text { (11) } \begin{aligned}
& \Delta \ln \left(1+\mathrm{i}_{\mathrm{t}}\right)-\Delta \ln \left(1+\mathrm{i}_{1}^{*}\right)-\Delta \ln \mathrm{F}_{\mathrm{t}}+\Delta \ln \mathrm{S}_{\mathrm{t}}=\mathrm{a}+ \\
& \mathrm{d}_{\mathrm{g}} \mathrm{UM} \mathrm{M}_{\mathrm{t}}+\mathrm{d}_{2} \mathrm{ME}_{\mathrm{t}}+\mathrm{e}_{\mathrm{t}} .
\end{aligned}
$$

Both anticipated money, $\mathrm{ME}$, and unanticipated money, UM, are included because, as a number of researchers found, these asset prices responded in a statistically significant way to both anticipated and unanticipated changes in the money stock. ${ }^{14}$ The finding that the individual markets respond significantly to $\mathrm{ME}$ is, itself, frequently taken as evidence that the markets are informationally inefficient. ${ }^{15}$ For the purpose of testing for CIP, however, the only relevant issues are whether the markets respond to $\mathrm{ME}$ and whether the responses net out in a way consistent with CIP.

If has been common to estimate equations like 6.9 or equation 11 over different subsamples to see if the markets' response to money announcements changes in response to changes in the Federal Reserve's operating procedure. ${ }^{16}$ Since the interest here is only in testing for CIP, however, there is no need to split this sample for this purpose: the difference in magnitude of the market's response is unimportant.

If is important to split the sample for another reason, however: the null hypothesis that $d_{1}=$ $d_{2}=0$ will not be rejected either if the markets do not respond to money announcements or if

. ME from equation 10 is likely to have little bearing on the test because ME and UM are nearly orthogonal. Furthermore, while the evidence on the importance of ME may be weak, the cost in terms of lost efficiency for including it is small.

15While this type of test is generally valid, there are some important limitations. For a discussion of these, see Pesaran (1987), especially chapter 8.

16 in October 1982, the Fed switched from a nonborrowedreserves to a borrowed-reserves operating procedure. See Thornton (1988a) for a discussion of the borrowed-reserves operating procedure. 
Table 1

\begin{tabular}{|c|c|c|c|c|c|c|c|c|c|c|c|c|}
\hline \multirow{3}{*}{$\begin{array}{c}\text { couniny } \\
6 \mathrm{ch}\end{array}$} & \multicolumn{3}{|c|}{ one nonin } & \multicolumn{3}{|c|}{ Throe Month } & \multicolumn{3}{|c|}{ Six Month } & \multicolumn{3}{|c|}{ Toefve norin } \\
\hline & 1 & $\mathrm{r}_{2}$ & $T_{3}$ & T. & 1 & T. & tro & 1 & T. & 1 & $T_{2}$ & T. \\
\hline & 00 & 27 & 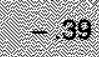 & 102 & -45 & -46 & 01 & $=45$ & 252 & 01 & 20 & -41 \\
\hline$s w$ & 02 & -12 & $=01$ & al & -34 & -03 & 02 & 32 & $=06$ & 00 & -32 & 0.9 \\
\hline GP & 65 & 28 & -18 & 08 & 42 & 21 & 104 & -46 & -24 & .05 & -46 & $=28$ \\
\hline FR: & 01 & 10 & $0-128$ & 00 & 23 & +126 & 00 & -29 & 1.30 & 60 & -28 & -13 \\
\hline Un & -01 & 2 & -7.7 & 02 & $=37$ & $=79$ & 06 & 38 & 82 & 00 & $=32$ & 64 \\
\hline A & 03 & -21 & , 55 & 00 & -27 & 156 & 01 & $=40$ & 155 & 00 & 01 & 10 \\
\hline
\end{tabular}

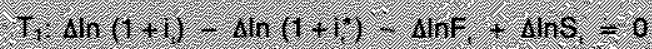

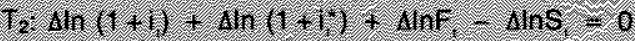

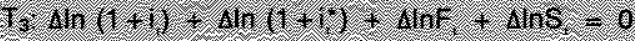

their response is consistent with CIP on average.

It is well-documented that the markets, especially U.S. interest rates, responded in a statistically significant way to unanticipated changes in the money stock through the early part of 1984. Their response after early 1984 is more problematic, however. Consequently, the period was divided into two subperiods: October 5, 1979, to January 29, 1984, and January 30,1984 , to September 14, 1988. ${ }^{17}$ Equations in the form of $6-9$ were estimated for both periods, and both anticipated and unanticipated changes in the money stock had a statistically significant effect only during the first subperiod. ${ }^{3}$ Consequently, estimates of equation 11 are presented only for the period ending in 1984 . Results for the more general test are presented for the entire period.

\footnotetext{
17For example, Dwyer and Hafez (1989) found that essentially there was no statistically significant response of U.S. interest rates to money announcements after July 1984. More importantly, estimates of equations of the form of 6-9 tound no statistically significant response to either anticipated or unanticipated changes in the money stock dur. ing the second subperiod.

TaEstimates of equations like 6-9 for the first subperiod indicate that the markets frequently responded significantly to anticipated changes in the money stock. This was the
}

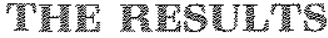

Table 1 reports t-statistics for tests of various linear combinations of changes in U.S. and foreign interest rates and spot and forward exchange rates, including the linear combination implied by CIP. The t-statistic for the linear combination implied by $\mathrm{CIP}$ is denoted $\mathrm{T}_{1}$; $\mathrm{t}$ statistics for two other linear combinations of the changes in these asset prices are denoted $\mathrm{T}_{2}$ and $\mathrm{T}_{3}$. The alternative linear combinations are interesting because $T_{2}$ is the instatistic for a test of a linear combination of changes in these asset prices that is correlated with that implied by CIP, while $T_{3}$ is the t-statistic for a test of a linear combination that is orthogonal to that implied by CIP. ${ }^{19}$ Consequently, if the null hypothesis that CIP holds cannot be rejected, it would not be surprising to find that $\mathrm{T}_{3}>\mathrm{T}_{2}>\mathrm{T}_{1}$.

case for U.S. and Canadian interest rates at all maturities, except the 12-month maturify for Canada, and is generally true for both the forward and spot exchange rates. It is not true for other foreign interest rates, with the exception of the one-month Euroyen rate.

19Let $R, R_{\text {, }}$ and $R$, denote the three restrictions on the vec. tor of changes in asset prices that correspond with $T_{1}, T_{2}$ and $T$, respectively, e.g., $R=(1,-1,-1,1)$. Then the correlation between $R_{1}$ and $R_{2}$ is -.50 , while $R_{3}$, and $R_{3}$ are uncorrelated. 
In every instance, the l-statistics for the test of CIP are extremely small, suggesting that CIP holds on average over the sample period. While supportive of CIP, the fact that the null hypothesis cannot be rejected is not compelling evidence because the same could be true of other linear combinations of these variables. Tests of other linear combinations produce t"statistics that are considerably larger than those for that implied by CIP, although in no case was the null hypothesis rejected. In the majority of cases, however, $\mathrm{T}_{3}>\mathrm{T}_{2}$

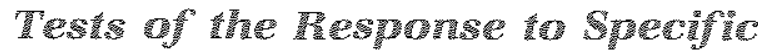 Irifornation}

Estimates of equation 11 along with the t-sta* tistics for tests of linear combinations of the changes in these variables for the period from October 5, 1979, through January 29, 1984, are presented in table 2. ${ }^{20}$ "wo F-statistics are reported. $F_{1}$ is a test that all of the coefficients are zero. $F_{2}$ is a test that the two slope coeffi. cients are zero.

There were four instances in which the coefficient on unanticipated changes in money was statistically significant at the $\mathbf{5}$ percent level and three instances in which the null hypothesis that both slope coefficients are zero is rejected. In no instance was the coefficient of anticipated money alone significant at the 5 percent level.

The occasional statistically significant response to unanticipated changes in the money supply is odd given the general lack of such responses. Even more surprising, one of these occurs at a maturity of six months while the other three occur at a maturity of 12 months, despite the fact there was no statistically significant response at shorter maturities. ${ }^{21}$ This fact along with the extremely low adjusted R-squares leaves open the possibility that the statistically significant responses are due to the influence of a relatively few observations. ${ }^{2 z}$
Scatter plots of the dependent variable and unanticipated changes in the money stock for the four instances in which the coefficient on UM was statistically significant are presented in figures 1-4. In the case of the six month maturity for Japan shown in figure 1 , it appears that two extreme observations (see arrows) could ae count for the significant positive coefficient on UM. The same two observations appear as extreme observations for the 12 -month maturity for Japan in figure 2 . To see if the results for Japan are sensitive to these observations, they were deleted and the equation was re-estimated. In both instances the coefficient on UM was no longer statistically significant at the 5 percent level. ${ }^{23}$

The Femaining scatter plots reveal no similarly dramatic outliers. They do indicate what the low adjusted R-squares suggest: a relatively weak relationship between the dependent variable and unanticipated changes in the money stock. ${ }^{24}$ Given the spherical nature of the scatter plots and the extremely low adjusted R-squares, these results do not represent a serious challenge to the null hypothesis that CIP holds on average.

Tests of linear combinations of changes in these variables reported in table 2 are similar to those for the entire period reported in table 1 . The major difference is the $T_{3}$ statistic is significant at the 5 percent level for Germany, France and the United Kingdom for all maturities. ${ }^{2, \overline{3}}$ This provides strong evidence that CIP holds on average during the period. This finding is con. sistent with that of Clinton (1988) who found that, even though there were numerous in* stances when deviations from interest rate pari. ty were larger than those implied solely by transactions costs, no profitable arbitrage opportunities exist on average.

Unlike Roley (1987) who rejected CIP for Japan, these results suggest that if holds for the
20France devalued its currency three times during this period, causing excessively large movements in the Eurofranc rate. These observations were deleted from tests involving money announcements for France. They were October 5, 1981, June 14, 1982, and March 21, 1983.

${ }^{21}$ Most of the emptrical evidence suggests that the response of U.S. interest rates to money announcements is the strongest at the shortierm maturifies. For example, see Dwyer and Hafer (1989) and Hafer and Sheehan (1989).

22Thornton (1988b, 1989) has shown that some of the reported statistically signifficant responses of U.S. interest rates, exchange rates and stock prices to unanticipated changes in the money stock are due to relatively few observations.

${ }^{23}$ The observations are March 7,1980 , and June 10, 1983. The t-statistics for the coefficient on UM are 0.97 and 1.69 for the six- and wolve-month maturities, respectively.

${ }^{24}$ Given the results reported here, there is little reason to perform formal statistical tests for the stabtity of the coefficients. In any event, such tests ikely will be of low power given the low adjusted R-squares for these equations.

25 Separate tests indicate that many of these asset prices do not follow a random walk. 


\section{Table 2}

The Markets' Reaction to Money Announcements: October 5, 1979 . January 27, 1984

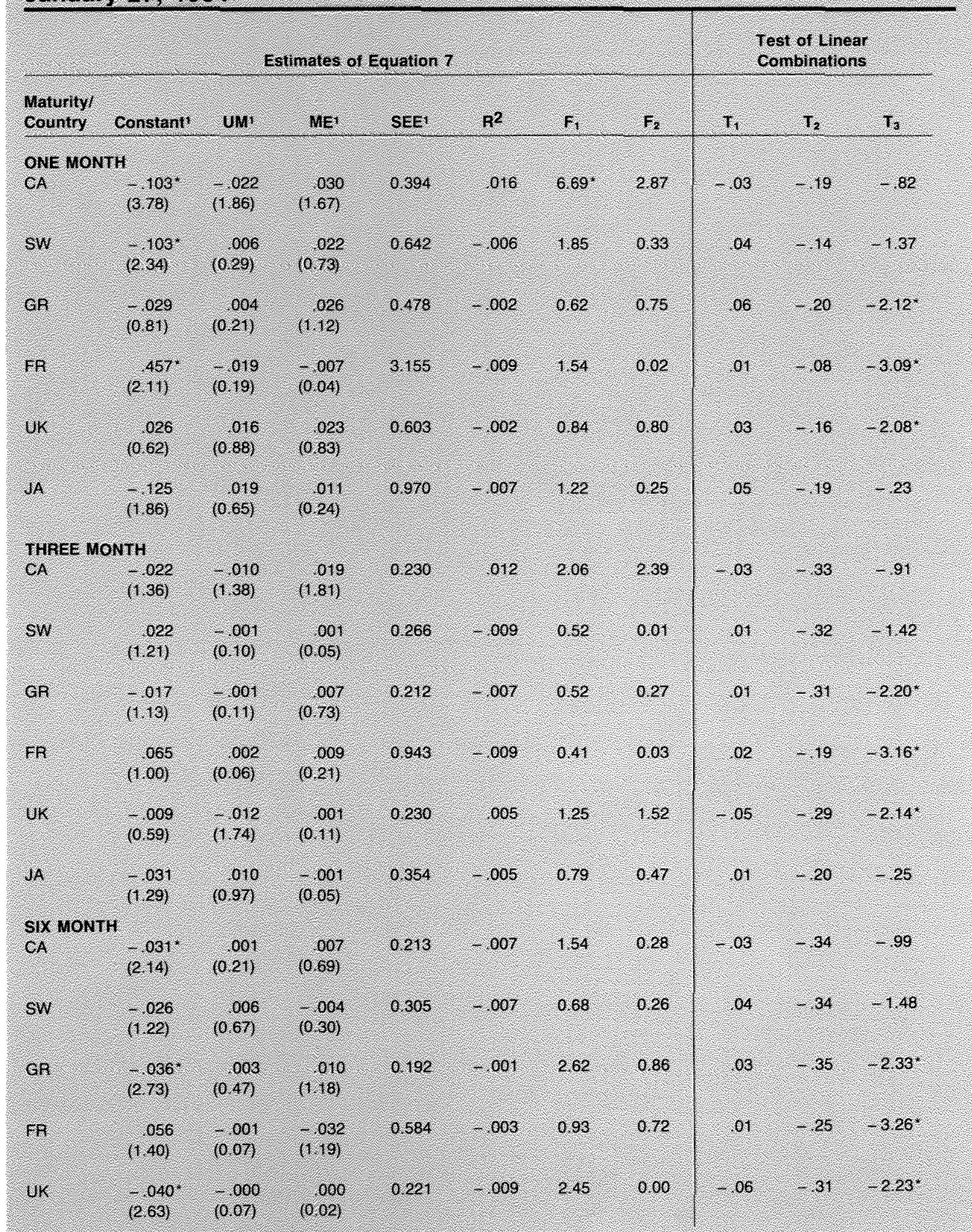


Table 2 (Continued)

The Markets' Reaction to Money Announcements: October 5, 1979 . January 27, 1984

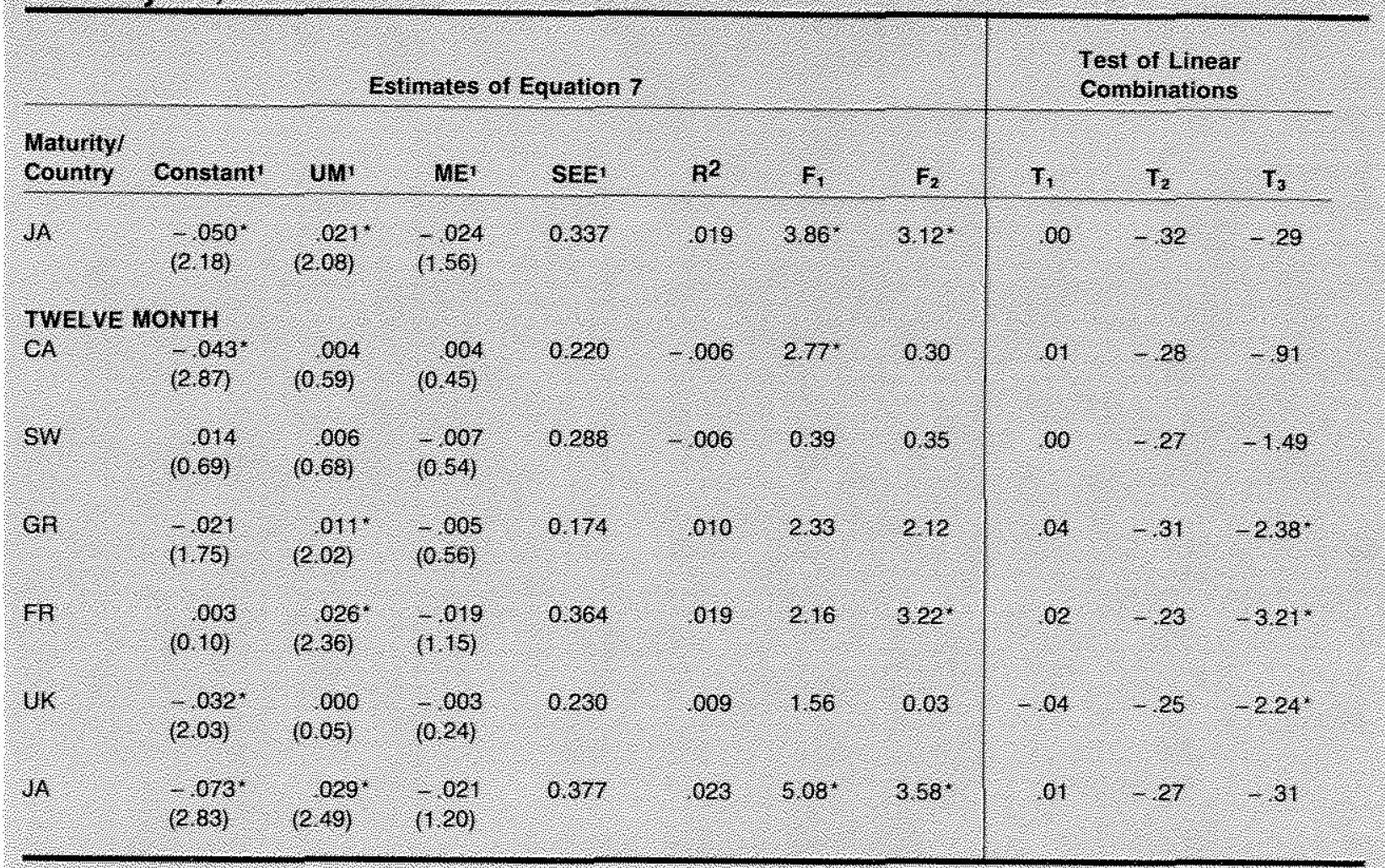

actuat coeficient is $10-2$ times the r poored coefficient

Thdcates statisticat signilicance at the 5 percent level.

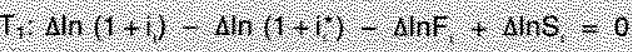

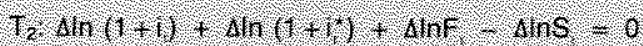

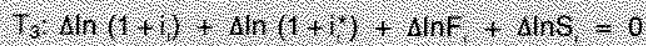

Euroyen rate. Roley used the Gensaki rate and attributed his failure to support CIP to capital controls. Since the Eurocurrency rates used here are not affected by capital controls, the results are not inconsistent with Roley's. Together, however, they suggest that there should be relatively weak substitutability between the Euroyen and Gersaki rates.

\section{Conflicting pesults for the $T_{1}$} Statistics and the Estimated In. terepept Coefficients

The $\mathrm{T}$, statistics reported in table 2 are much smaller than the t-statistics for the intercept terms, some of which were significant at the 5 percent level. ${ }^{25}$ One explanation for this, which

${ }^{26}$ Equation 11 was also estimated using all of the daily data, not simply for days when there was a money announcement. Not surprisingly, the t-statistics for the intercept

terms were not much different from the t-statistics for the linear combination of these asset prices implied by CIP reported in table 2. 
Figure 1

Scatter Plot For Japan: Six-Month Maturity

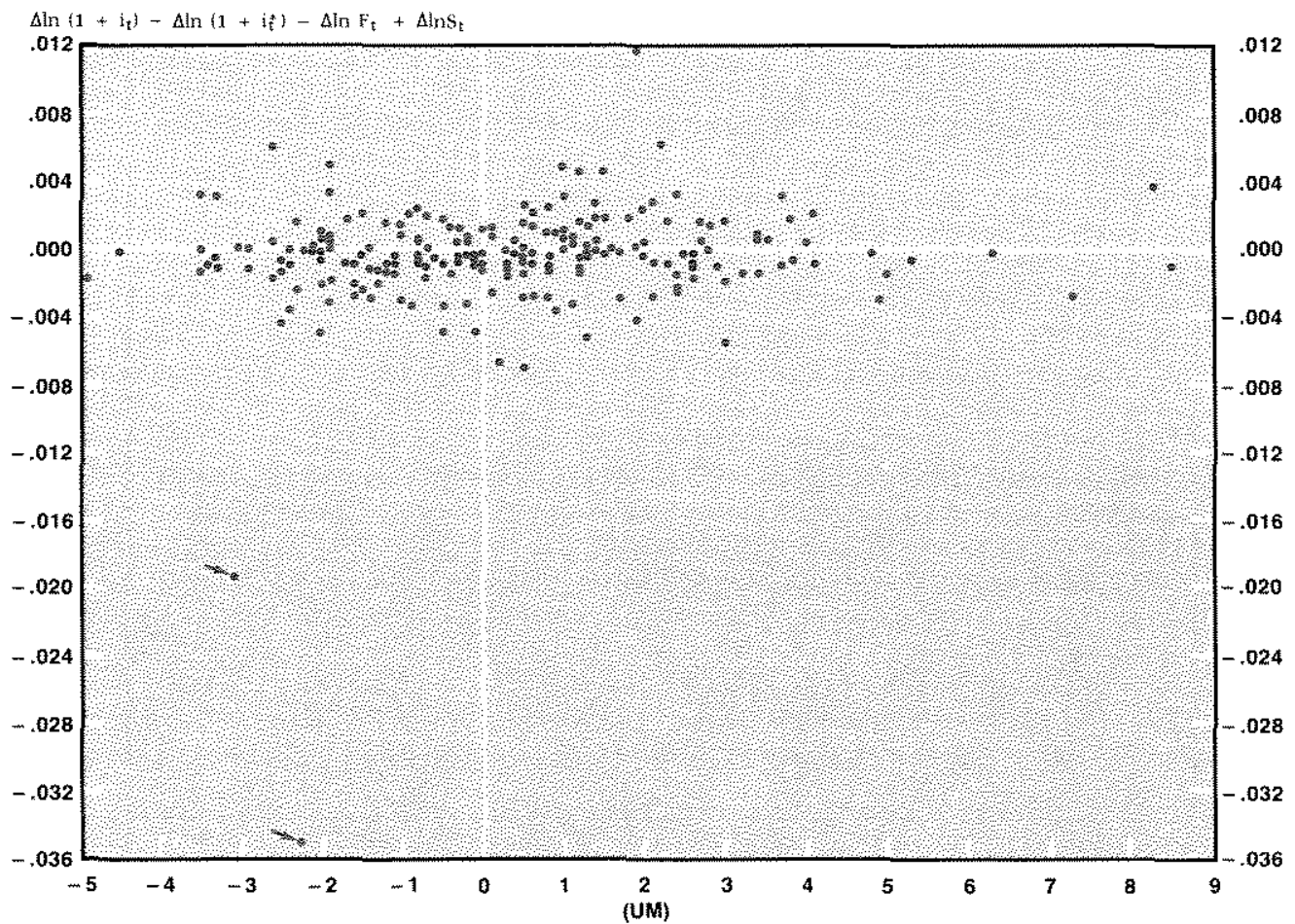

Figure 2

Scatter Plot For Japan: 12-Month Maturity

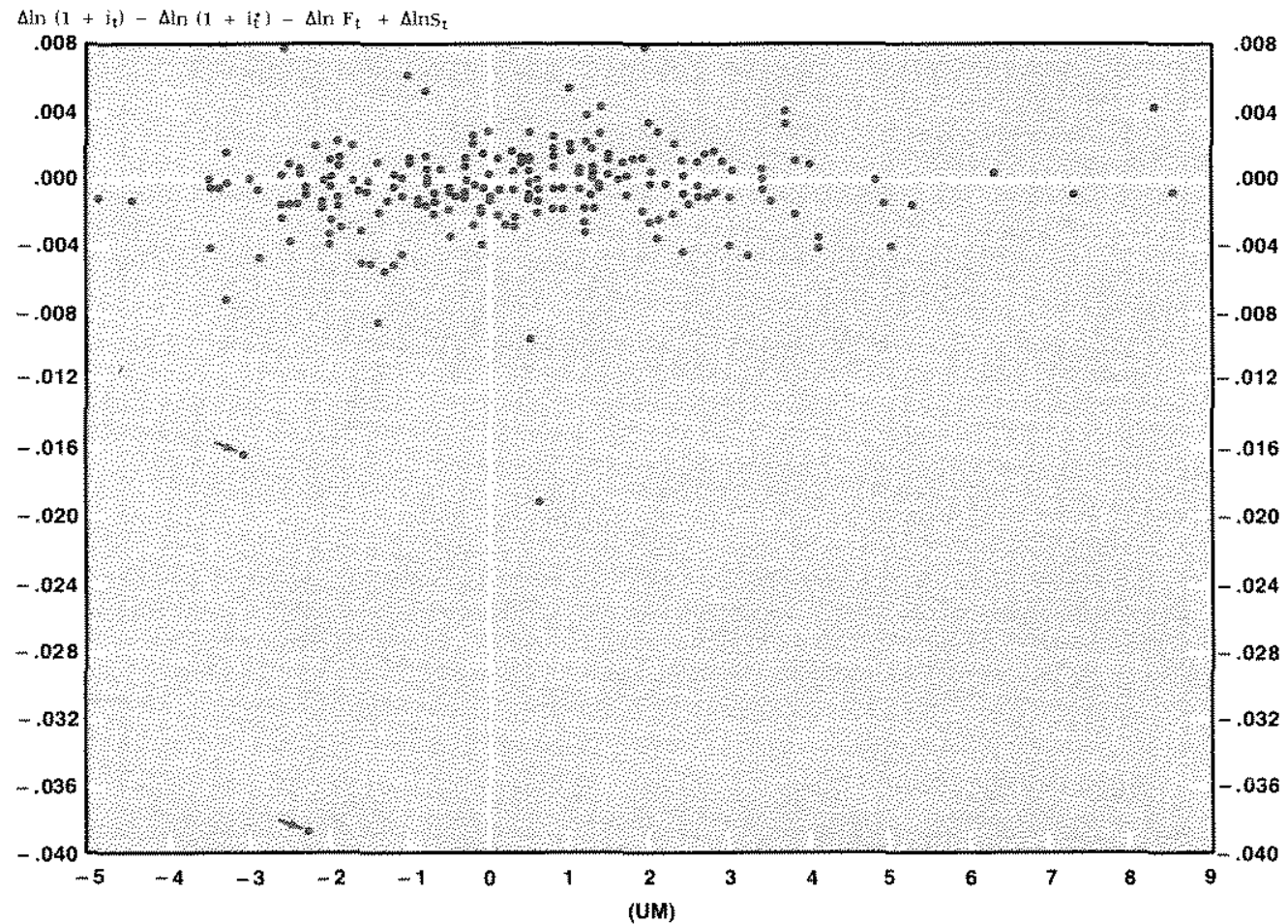


Figure 3

Scatter Plot For Germany: 12-Month Maturity

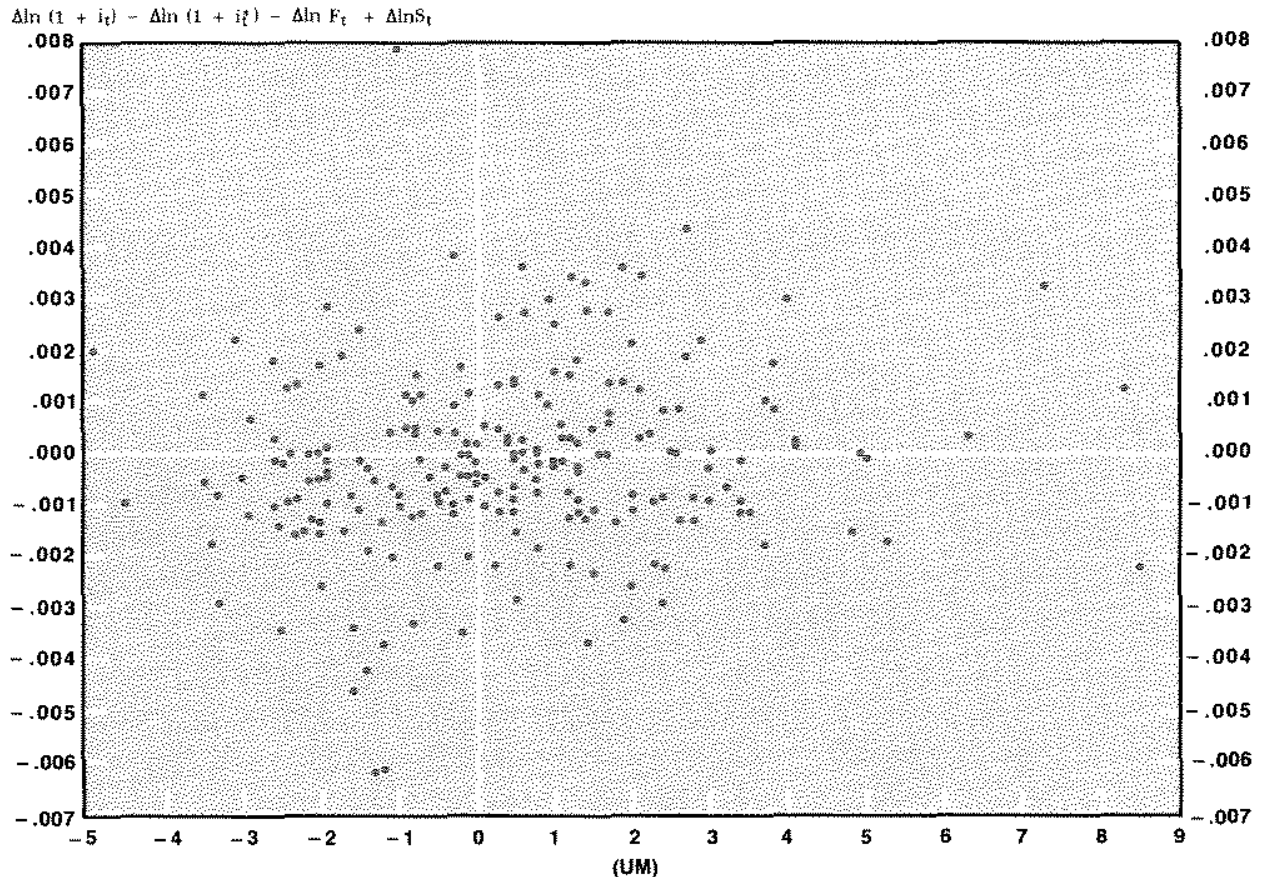

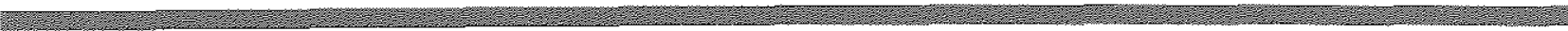

Figure 4

Scatter Plot For France: 12-Month Maturity

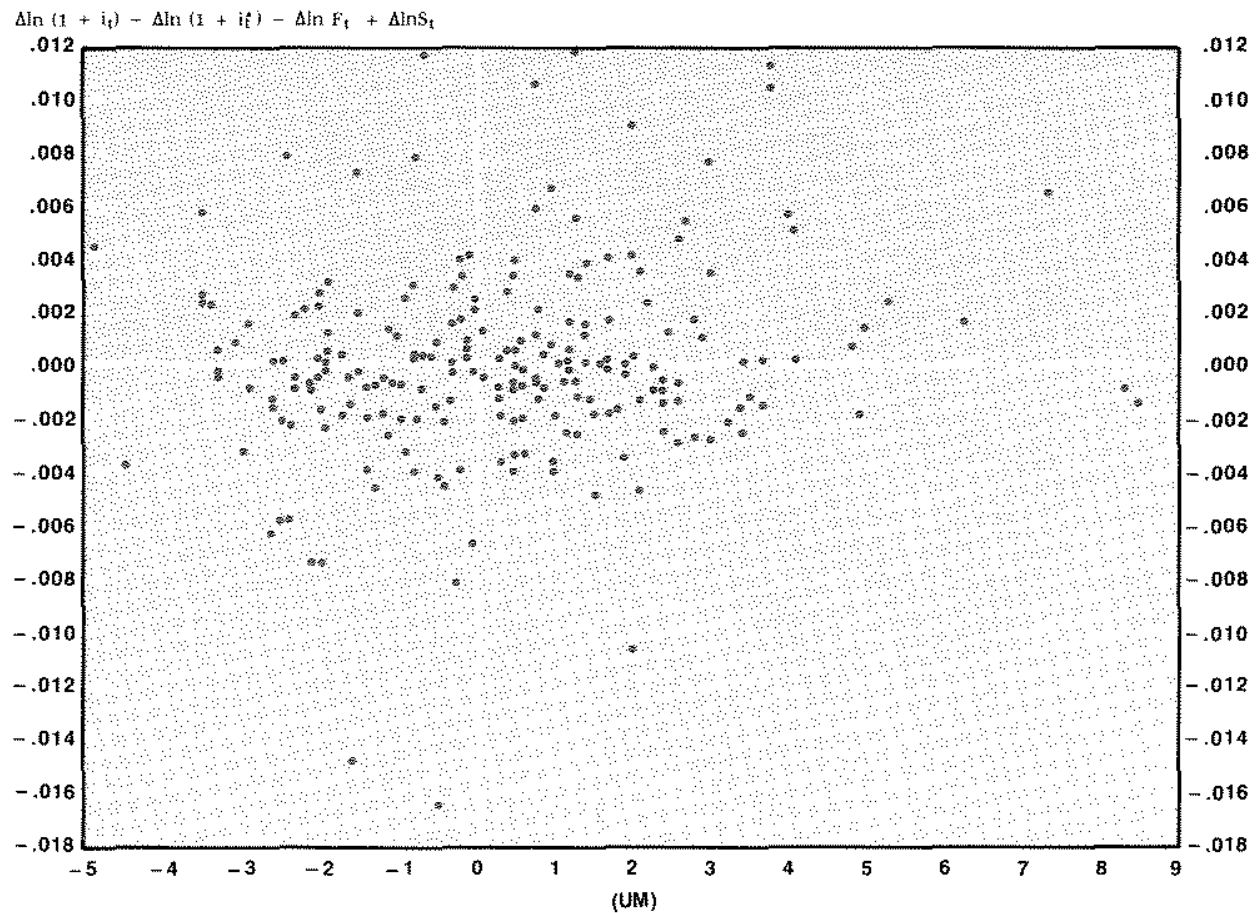


is consistent with the frequent-though not persistent-violations of CIP using transaction cost data, is that shocks to the market in the form of money announcements are destabilizing, causing large deviations from CIP on these days. ${ }^{27}$ If this is the case, deviations from CIP should be larger on money-announcement days. Consequently, not only will the means be larger, but the variance of the dependent variable in equation 11 should be larger on moneyannouncement days as well. $z z$

rable 3 reports test of the equality of the variances of the dependent variable of equation 11 against the alternative that the variance is larger on money-announcement days. These tests are performed only for the period ending in 1984 because, as has been noted, the individual markets do not respond significantly to unanticipated changes in the money stock thereafter.

In general, the results are not consistent with the hypothesis that the variance is larger on money-announcement days. There are six instances in which the null hypothesis of the equality of the variances is rejected in favor of the alternative at the 5 percent significance level, but there are seven instances in which the variance of the dependent variable is significantly lower on money-announcement days. ${ }^{29}$ Moreover, two of the former cases are for the six- and 12-month maturities for Japan. Since the previous results for these maturities were strongly influenced by these observations, they were deleted and the tests repeated. When this was done, the null hypothesis was no longer rejected in favor of the alternative in either case. ${ }^{30}$ Consequently, the occasional significant intercept term and the occasional significantly larger variance on money-announcement days are not strong evidence against CIP holding on average.

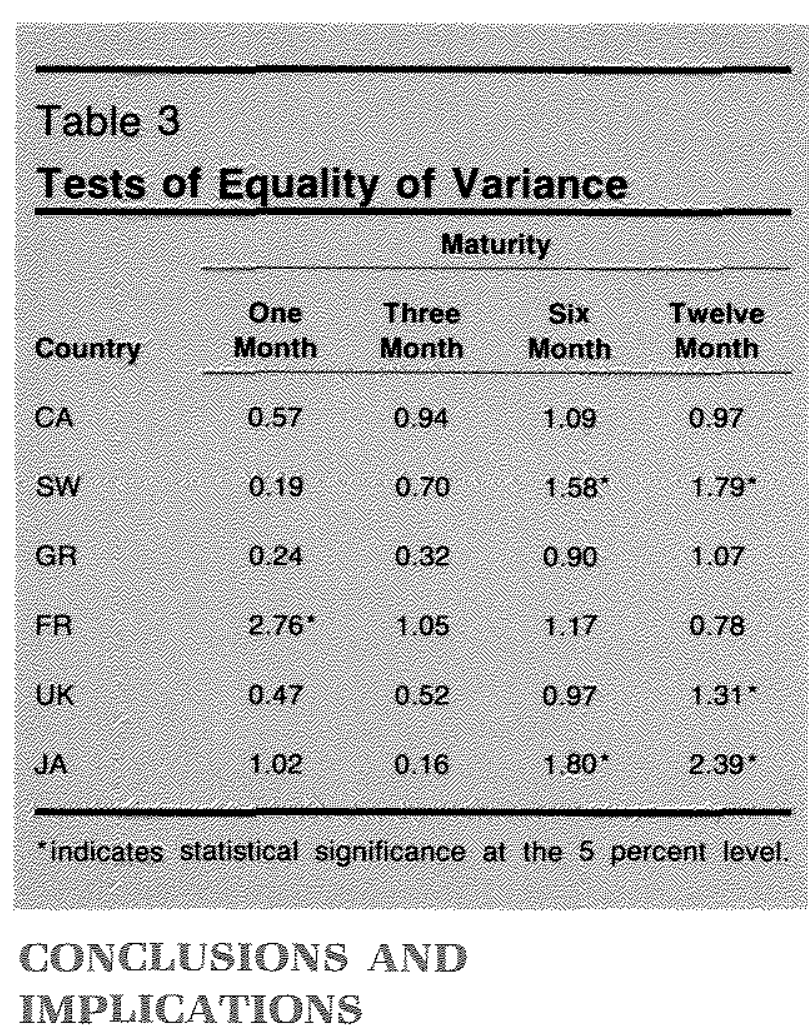

Despite a few occasions in which there was a statistically significant response to unanticipated changes in the money stock, the results of tests of the markets' response to economic news are consistent generally with the hypothesis that CIP holds on average. In two of the four instances in which there was a significant response to unanticipated changes in the money stock, the results appeared to be due to the nature of the data and the sensitivity of leastsquares to extreme observations. Also, the few instances in which the means of the dependent variable implied by CIP were significantly different from zero on money-announcement days do not constitute strong evidence against CIP.
2"Another is that the difference in these results are due to the distributions of the dependent variable. Though not reported here, the distributions of the dependent variable have their probability mass more highly concentrated about the mean and have thicker tails than normally distributed random variables. Consequently, sample means vary considerably, even in what conventionally would be large samples. The evidence of this is obtained from tests derived from histograms constructed by dividing the interval from \pm 2.33 standard deviations around the mean into 11 equal-sength groups centered on the mean. The first and last group were open-ended, theoretically containing 1 percent of the sample in each. These histograms were created for all observations and for days when there were and were not money arnouncements for the first subperiod. In nearly all instances, the actual frequency in the first and last group exceeded-in many cases, greatly exceeded-the expected frequency. But even in those in- stances where this was not the case, the actual frequency in the tirst and last group exceeded the actual frequencies in the second and third and 11 th and 12th groups. The null hypothesis of normality was rejected in every case at very low significance levels by formal chi-square goodness-of-fit tests.

${ }^{28}$ One way to conceptualize this is simply to note that there is an extra source of variation on money-announcement days. For an example, see Thornton (1988b).

29This may not be too surprising given the transaction-cost interprefation of the error term because Bahmani-Oskooee and Das (1985) report that their estimates of transaction costs were highly unstable.

30The F-statistics for the six-and 12 -month maturities are 0.72 and 1.14 , respectively. Indeed, for the six-month maturity, the variance is significantly smaller on moneyannouncement days. 
This is so because the hypothesis that the mean of the dependent variable implied by CIP is zero was never rejected for larger samples using all of the daily observations.

There is no evidence that the data are consistently more variable on money announcement days. Furthermore, the t-statistics for tests that linear combinations other than that implied by CIP were zero were much larger than those for that implied by CIP and, in several instances, the null hypothesis was rejected during part of the sample period. Hence, CIP appears to hold on average for these data.

There are several policy implications of the finding that, on average, an exact linear relationship exists between the U.S. and foreign interest rates and the spot and forward exchange rates. For example, if the U.S. interest rate is taken as exogenous, foreign central banks cannot independently and simultaneously control both their interest rates and their exchange rates. This means that small open economies are susceptible to exogenous changes in U.S. monetary policy. Finally, the results indicate the CIP assumption used in many theoretical models is appropriate, so long as it is not required to hold at every point in time. These results, however, do not provide evidence for the question of market efficiency which characterizes many discussions of CIP and covered interest. arbitrage.

\section{PEFERENCES}

Bahmani-Oskooee, Mohsen and Satya P. Das. "Transaction Costs and the interest Parity Theorem," Joumal of Political Economy (Alugust 1985), pp. $793-99$.

Belongia, Michael T, and Fichard G. Sheehan. "The Infor" mational Efficiency of Weekly Money Announcements: An Econometric Critique," Journal of Business and Economic Statistics (July 1987), pp. 351-56.

Belongia, Michael T., R. W. Hafer, and Richard G. Sheehan. "A Note on the Temporal Stability of the Interest RateWeekly Money Relationship," Federal Reserve Bank of St. Louis, Working Paper 86-002 (1986).

Callier, Phillips. "One-Way Arbitrage and its Implications tor the Foreign Exchange Markets," Journal of Political Economy (December 1981), pp. 1177-86.

Chrystal, K. Alec, and Daniel L. Thornton. "On the Intormational Content of Spot and Forward Exchange Rates," Jour nal of international Money and Finance (September 1988), pp. 321-30.
Clinton, Kevin. "Transactions Costs and Covered Interest Arbitrage: Theory and Evidence," Journal of Political Economy (April 1988), pp. 358.70.

Comell, Bradford. "The Money Supply Announcements Puzzle: Review and Interpretation," American Economic Review (September 1983), pp. 644-57.

Deardorif, Alan V. "One Way Arbitrage and Its Implications for the Foreign Exchange Markeis," Journal of Political Economy (Apri 1979), pp. 351w64.

Deaves, Richard, Angelo Melino, and James E. Pesando. "The Response of Interest Rates to the Federal Reserve's Weekly Money Announcements: The Puzzle of Anticipated Money," Journal of Monetary Economics (May 1987), pp. 393-404.

Dufey, Gunter, and lan H. Giddy. The International Money Market (Prentice-Hall, 1978).

Dwyer, Gerald P., and R. W. Hafer. "The Response of interest Rates to Economic Announcements;" this Revjew (March/April 1989), pp. 34-46.

Engle, Robert F. "Autoregression Conditional Heteroscedasticity With Estimates of the Variance of United Kingdom In flation," Econometrica (July 1982), pp. 987-1008.

Hafer, R. W., and Richard G. Sheehan. "The Response of Interest Rates to Unexpected Weekly Money: Are Policy Changes Important?" unpublished manuscript, March 1989.

Hardouvelis, Gikas A. "Market Perceptions of Federal Peserve Policy and the Weekly Monetary Announcements," Journal of Monetary Economics (September 1984), pp. 225-40.

Husted, Steven, and John Kitchen. "Some Evidence on the international Transmission of U.S. Money Supply Announcement Effects," Journal of Money, Credit and Banking (November 1985), pp. 456-66.

Kubarych, Roger M. Foreign Exchange Market in the United States, revised ed. (Federal Reserve Bank of New York, 1983).

Lo, Andrew W., and A. Craig Mackinlay. "An Econometric Analysis of Nonsynchronous Trading:" NBER Working Paper No. 2960 (May 1989).

Pesaran, M. Hashem. The Limits to Rational Expectations, (Blackwel, 1987).

Roley, V. Vance. "U.S. Money Announcements and Covered Interest Parity: The Case of Japan:" Journal of International Money and Finance (March 1987), pp. 57-70.

Sheehan, Richard G. "Weekly Money Announcements: New information and ts Etfects," this Review (August/September 1985), pp. 25-34.

Tandon, Kishore, and Thomas Urich. "International Market Response to Announcements of U.S. Macroeconomic Data." Journal of International Money and Finance (March 1987), pp. 71-83.

Thornton, Dantel L. "The Borrowed-Aeserves Operating Procedure: Theory and Evidence," this Review (Januaryl February 1988a), pp. 30-54.

"Why Do Market Interest Rates Respond to Money Announcements?" Federal Reserve Bank of St. Louis Working Paper No. 88-002 (1988b).

"The Effecl of Unanticipated Money on the Money and Foreign Exchange Markets," sournal of international Money and Finance (forthcoming). 